\title{
Analysis of Total Quality Management to Promoting the Application of MRP System
}

\author{
${ }^{1}$ Muhammad Asim and ${ }^{2}$ Huey Fang Pasha \\ ${ }^{1,2}$ University Marketing, Admissions and Communications, Monash University, Malaysia \\ ${ }^{1}$ raphaelfang@monash.edu
}

\begin{abstract}
Article Info
Journal of Journal of Enterprise and Business Intelligence (http://anapub.co.ke/journals/jebi/jebi.html)

Doi: https://doi.org/10.53759/5181/JEBI202101019

Received 15 April 2021; Revised form 18 July 2021; Accepted 22 August 2021.

Available online 05 October 2021.

(C2021 Published by AnaPub Publications.

Abstract - The current study considers the existence of relationships of association and influence between the overall quality management and MRP system. It happens by surveying (70) employees of Royal Color company in Sulaimaniyah. It has relied on several statistical means to study the relations between these two variables within a comprehensive framework. The research discusses whether or not there are a correlation and effect between the overall quality management and MRP system through the use of a Spearman correlation coefficient. The study has provided numeral inferences. The most essential is an important positive association among the overall quality management and MRP system. Such investigation also made a series of references consistent with those proposals.
\end{abstract}

Keywords- Comprehensive Quality Management; MRP System; Link and Impact Relationships; Royal Colors Company.

\section{INTRODUCTION}

There is no doubt that the age we live in has brought profound and enormous changes to everything in our lives. Overall, quality management is no longer a secret of the rich and elites and the source of their influence and power. Comprehensive quality management $(\mathrm{CQM})$ is no longer a rare and difficult wealth to collect. The revolution in communications and information and its tools, especially the Internet, has made overall quality management a required goal for every industrial or business organization. Whether the organization is successful or unsuccessful, whether it is voluntary or spontaneous, the challenge is how to deal with it [10]; How to harness the overall quality management to produce high-quality services and products? How do they spread among employees, and how do you develop to create new and innovative knowledge? The system's view and handling continue to be based on the saying, "Work as a source of power." Hence, the role of CQM in promoting uses of MRP system in the organization. Various contemporary organizations are increasingly interested in applying modern technologies in their various production processes, including the planning and controlling production and the underage to achieve the optimal exploitation of available productive resources and capacities. It is essential to make an active contribution to achieving the organization's strategic objectives [9].

Literature review

The intellectual framework for overall quality management TQM

In table 1, It is shown by [14] that the term TQM refers to the pursuit of organization quality. In such an approach, there are 3 main philosophies. The first for improving it is pushing that never-ending. As improvement is continuous, CQM systems aim to prevent poor quality [7]. It is considered a philosophy that emphasizes 3 principles to achieve high process quality and performance levels. Such principles are associated with (1) the satisfaction of customers, (2) the participation of employees, and (3) continuous performance improvement. [15] believes that overall quality management is a way of thinking that becomes an essential element of the organization. It is defined as a tool of management, philosophy, and principles set that guide each organization member in continuous improvement to meet customer satisfaction. The concept of CQM includes all organization members in deciding due to their involvement [1]. The impact is serious to all activities of the business to provide services to customers with high-quality products. 
Table 1. Key elements of the pioneers of overall quality management

\begin{tabular}{|l|l|l|l|l|l|}
\hline $\begin{array}{c}\text { Theories and } \\
\text { concepts }\end{array}$ & \multicolumn{1}{|c|}{ Deming } & \multicolumn{1}{|c|}{ Juran } & \multicolumn{1}{|c|}{ Feigenbaum } & \multicolumn{1}{|c|}{ Ishikawa } & \multicolumn{1}{c|}{ Crosby } \\
\hline $\begin{array}{l}\text { The concept } \\
\text { of quality }\end{array}$ & $\begin{array}{l}\text { Three angles of } \\
\text { quality: product, } \\
\text { user, and } \\
\text { instructions }\end{array}$ & Suitable for use & $\begin{array}{l}\text { What does the } \\
\text { ?customer say }\end{array}$ & $\begin{array}{l}\text { Convincing the } \\
\text { customer }\end{array}$ & $\begin{array}{l}\text { Compliance } \\
\text { with } \\
\text { requirements }\end{array}$ \\
\hline Philosophy & $\begin{array}{l}\text { Purpose stability, } \\
\text { statistical } \\
\text { analysis }\end{array}$ & Project approach & $\begin{array}{l}\text { Full customer } \\
\text { satisfaction and } \\
\text { economic cost }\end{array}$ & $\begin{array}{l}\text { Quality control } \\
\text { throughout the } \\
\text { organization }\end{array}$ & Zero flaw \\
\hline Curriculum & $\begin{array}{l}\text { Statistical } \\
\text { techniques }\end{array}$ & $\begin{array}{l}\text { Three-quality: } \\
\text { planning, and } \\
\text { control, and } \\
\text { improvement }\end{array}$ & $\begin{array}{l}\text { A systems } \\
\text { approach to } \\
\text { comprehensive } \\
\text { quality control }\end{array}$ & Data speaking & Motivating \\
individuals \\
\hline Mechanisms & $\begin{array}{l}\text { The } \\
\text { commitments in } \\
\text { management }\end{array}$ & $\begin{array}{l}\text { Diagnostic and } \\
\text { therapeutic } \\
\text { journeys }\end{array}$ & $\begin{array}{l}\text { The nine success } \\
\text { factors }\end{array}$ & $\begin{array}{l}\text { The seven } \\
\text { statistical tools }\end{array}$ & The 14 steps \\
\hline
\end{tabular}

Source: [16]

The ideas of the pioneers of comprehensive quality are the ones that have dominated the movement of quality in the human field, and there is a constant quest for change and development in this field. These ideas addressed certain issues and became theories in the field of administrative and human sciences.

The ideas of these pioneers became the structure of knowledge on which many practices were built. [10] identifies that there are three key principles for CQM: inclusive - including each member of the organization. Quality - The customer (in this case, the student) the requirements are met. Management - Senior Leadership fully supports and participates in the process and select [12] a comprehensive critical factor list for CQM application Table (2).

Table 2. Comprehensive critical factors list for CQM application

\begin{tabular}{|l|l|l|}
\hline $\begin{array}{l}\text { Commitment to leadership and } \\
\text { senior management }\end{array}$ & Education and training & Quality Culture \\
\hline Continuous improvement & Strategic management & Reference comparison \\
\hline Resource quality management & Monitoring statistical processes & Product process and design \\
\hline Focus on customers & Quality information analysis & Operations Management \\
\hline Staff participation & Quality assurance & Product innovation \\
\hline Empowering staff & Quality of citizenship & Knowledge Management \\
\hline
\end{tabular}

Source: [12]

The principles and procedures for CQM are shown in Table (3) can also be visualized through the list of principles and procedures below. It is very simple to understand recent developments in the practice of CQM, which are [9].

Table 3. The principles and procedures for CQM

\begin{tabular}{|l|l|}
\hline Principles & Procedure \\
\hline Portal & Management and leadership involvement \\
\hline Range & Company-wide participation after grade \\
\hline Field or scale & Everyone has some responsibility and or \\
\hline Philosophy & Prevention, not detection \\
\hline Standard & .Do it right from the first time \\
\hline Control & Quality cost \\
\hline Method & Improvement being continuous \\
\hline
\end{tabular}


TQM's implementation philosophy indicates the organization, regardless of its current style management or culture of the organization and its clients.

To a set of stages, since TQM can't be employed overnight, there are phases that the process of implementation must go through as well as time that varies from organization to organization. In general, however, the number of stages [9] has been determined by the following:

- Phase A: Why TQM, Jeopardies, Melasma, and advantages: Management must not delve into the application of CQM with no testing overall management quality implications. It is on management practices and all supporting and core work and human resources deployment [2]. Furthermore, the cost of implementing CQM through culture as new works. Thus, making the essential alterations must be prepared carefully. Assessing benefits - often longterm and more difficult is a further challenging assignment. As it implicates a great uncertainty deal in terms of market expansion, reducing the cost of manufacturing by reducing quality costs, and improving stakeholder satisfaction. Convinced that CQM can significantly increase production and business-enhancing results if management decides to adopt a CQM system. Otherwise, TQM may later be found as not achieving the expected results and may be resolved.

- Stage B: Create a vision. Setting the quality message: This goal is an important step in putting TQM on organizational track. Despite when the mission and visibility data are existing, it needs to be reconsidered to render it the actual force of driving behind TQM. Achievable and concrete performance objectives should be set in important business processes with due diligence and shared with all persons concerned.

- Phase C: Strategic selection includes: systematic areas identification (including processes of supporting and core). There is a clear area of improvement for performance because such improvement is necessary for survival or growth. Systematic practice evaluates the problem extent and nature and assesses the potential consequences of deficiencies in manufacturing costs, shares of the market, and margins of profit. A comprehensive mechanism must be in place to collect the data required for the mentioned analysis from diverse sources outside and within the organization and so on [8]. Develop action as the plan being comprehensive in expressions of tasks or activities to be performed, following the sequence, human resources, knowledge, and skills to be organized, supervision and oversight to be carried out, etc. The implementation of the action plan is strict and time-bound. Pro-active steps monitoring is used to provide feedback on whichever alterations to the implementation plan, when necessary, to gain confidence again.

\section{MRP'S INTELLECTUAL FRAMEWORK}

The Concept of Materials Needs Planning System (MRP): Materials Requirements Planning is responding to the changing several companies' requirements for managing system of production. It delivers the derivative demand and demand reservoir. [14] sees a methodology as used to plan bundled products production, i.e., smartphones, cars, tables of kitchen and other products whole host which are collected. Certain substances are manufactured frequently, whereas others in batches are manufactured. Such procedure arises with the main schedule production. [13] sees it as a computerized planning and control system that enables the company to manage thousands of products and spare parts, constantly change priorities, and meet unexpected demand. [6] identified as a computerized information system that would particularly assist in managing approved demand deposits and scheduling orders to re-enhance the reservoir's size. He adds [4] all systems of planning and control of production, including MRP, aims to find the best way to produce products.

It meets the requirements and desires of different customers with the characteristics and specifications of the product within the scope and limits of a set of administrative, financial, and technical restrictions and limitations [3].

Decisions adopted on planning and production control systems affect and store in a range of competitive precedents (cost, quality, delivery dependability, scheduling efficiency. MRP mentions planning as a mathematical tool according to the chief production scheduling to determine the approved components' needs (derived), such as raw materials, basic parts, and subgroupings. It not only uses this system in the manufacturing environment but also adapts to the distribution and storage environment by knowing the current levels of the treasury and the list of materials included in the final product composition of the specified product.

MRP explains the materials quantities and types obtained from organizations outside considering the treasury's current levels. The types and quantities of materials that can be manufactured internally consider the current levels of the treasury.

At whichever time such orders are supplied (obtaining from abroad, internally manufactured) considering periods of waiting set for such materials. [11] has defined it as "a set of logical and sequential procedures, complementary to each other. It is the design of special restrictions to translate the main production scheduling into each component of 
inventory's net needs - the time required to provide it so that the industrial company can meet its obligations to its customers. MRP is involved with the control of inventory and scheduling production. It is a system of controlling material that tries to maintain sufficient stock levels to ensure that the needed materials are available when required.

MRP is appropriate in multiple items cases along with complex material bills. MRP is particularly suitable for manufacturing settings as the request for various components, and sub-clusters depends on the elements' requirements facing demands as external.

MRP systems have been developed to better cope with the order elements. [14] sees a methodology as used to plan bundled products production, i.e., smartphones, cars, tables of kitchen and other products whole host which are collected. Certain substances are manufactured frequently, whereas others in batches are manufactured.

Such procedure arises with the main schedule production. The basic Table determines an assembled product expiry time and quantity. It is frequently mentioned as the final component. The material necessities planning then creates a production plan for the final element, indicating subgroups timing and quantities, parts of a component, and raw materials needed to assemble that final element.

This sequence is shown in Figure (1).

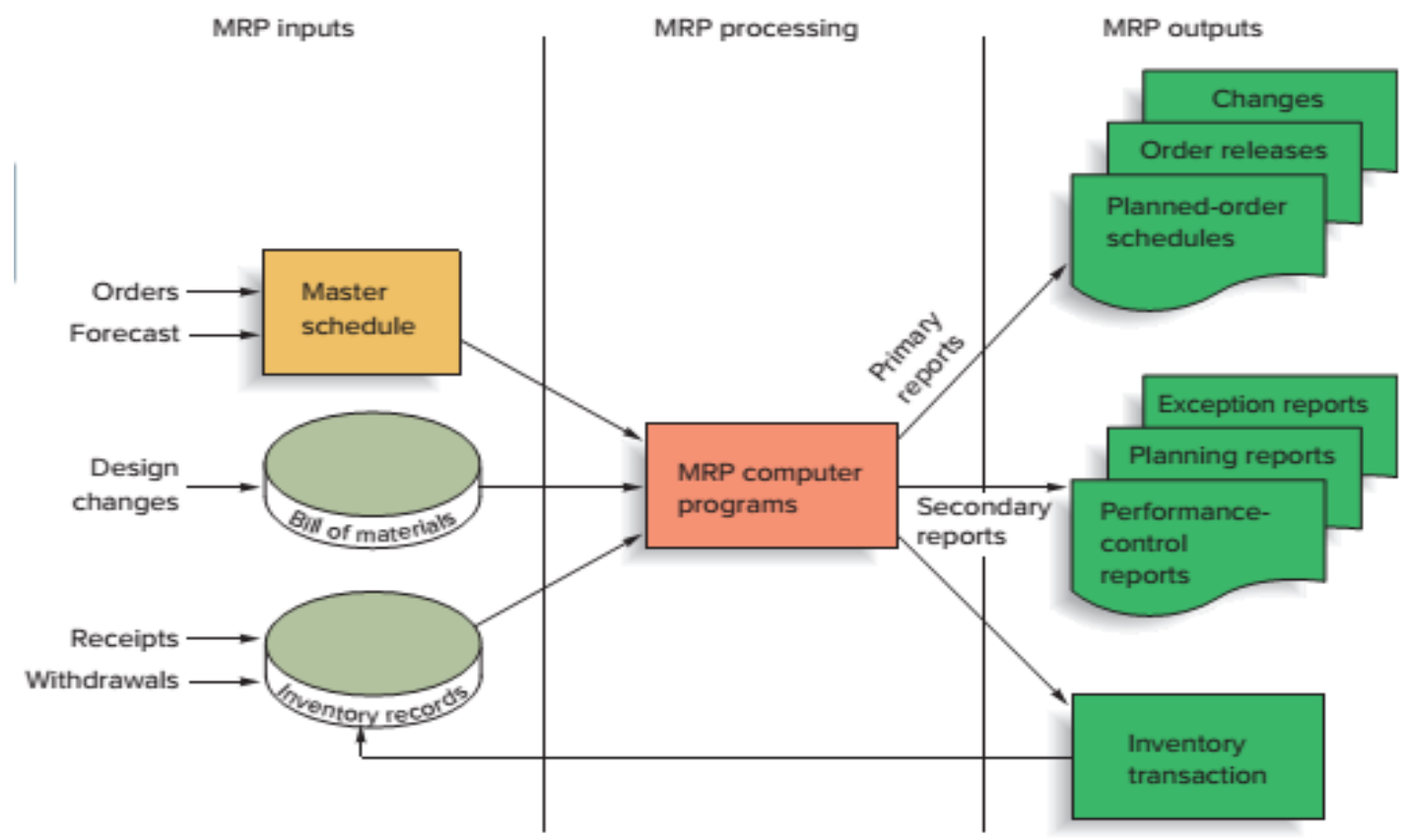

Fig 1. Inputs, outputs and system processes MRP [14]

[13] defines the MRP system as the core of the integrated production system. It contributes to facilitating the administration's planning production task of capacity and controlling production lines, and raising management's procurement efficiency [5]. It is a method for timing and calculating the needs of industrial materials with Derivative demand. The application of MRP is the application is primarily utilized by companies that produce services or goods. MRP system responds to inquiries, i.e., if a product is manufactured, how much required raw materials are, and ensuring the right time to business continuity.

Nevertheless, every company has its options as a unique software. It needs to adjust factors of the operating system, i.e., MRP, in a company. In the current study, we planned to identify difficulties and identify the briquette product needs for preventing problems in planning material requirements and analyzing the existing situation. The obtained data has been processed in the direction of the specific requirements in a computer program, and the requirements materials have been planned. In this context, this system aims to define a production system in managers' and employees' terms. Given all the above, we can find a comprehensive definition of the MRP system. "It is a system for planning production and controlling inventory automatically and assisting in calculating the demand for materials constituting the final products. Goods or services provide these materials according to the requirements of the 
production plan, and at the required time, without resorting to the large and continuous storage of these materials. Studies indicate that the cost of storage in organizations Al-Sinaiyah may reach $30 \%$ of the inventory value.

Methodology

It has become clear today and unquestionably. TQM represents one of the contemporary intellectual developments in the philosophy of modern management and effective practice of its practices most appropriate to the rapid changes in business and organizations. The study started from a basic problem that (how can management contribute Total quality in enhancing the application of the MRP system?) through practical application in one of the industrial companies. It is the Royal Colors Printing Company with Flexo Technology and packaging food and nonfood products. This study also seeks to achieve the following main goals: 1- Providing a theoretical framework on total quality management, its importance, and functions. 2- Defining and analyzing the importance and challenges. They stand in the way of the industrial sector adopting total quality management by adopting modern technologies such as MRP technology and taking it with reasons for the advancement of knowledge. 3- Moving awareness and awareness among the organization's productive elements under the discussion of the importance of investing in total quality management. Also, it exploits the large knowledge stock available to them in applying the latest available technologies, including material needs identification technology (MRP), to raise the level of work performance therein. The study is based on hypotheses: The first hypothesis: There is a significant correlation between total quality management and the MRP system. The second hypothesis: There is a significant effect relationship between TQM and the MRP system. The study was based on the survey methodology, as it is the closest approach to the study's nature.

\section{RESULTS}

To identify the nature of the relationships of association and impact between the Overall Quality Management and the MRP system, the researchers distributed 70 questionnaires. They were fully retrieved, i.e., the response rate was $100 \%$ agency.

\section{The correlation between $C Q M$ and MRP}

Table 4. Relationship results in Spearman between CQM and system MRP

\begin{tabular}{|c|l|}
\hline $\begin{array}{c}\text { Independent changer } \\
\text { Approved changer }\end{array}$ & CQM \\
\hline System Mrp & $0.926^{*}$ \\
\hline $\mathrm{N}=70$ & $\mathrm{P} \leq 0.05$
\end{tabular}

Source: Prepared by researchers in the light of computer results

Table (4) shows a significant positive correlation between overall quality management as an independent variable with the value of the total correlation coefficient index $\left(0.926^{*}\right)$ at a significant level of 0.05 . This finding suggests that the more the lab is interested in managing overall quality, the more it will enhance the MRP variant. Based on the above, the first main hypothesis is accepted at the level of the researched laboratory.

Impact relationships between CQM and MRP system

Table 5. The impact of overall quality management in the system MRP

\begin{tabular}{||l|l|l|l|l|l||}
\hline Variable & \multicolumn{2}{|l|}{ CQM } & \multicolumn{2}{|l|}{ F } \\
\cline { 2 - 6 } & $\beta 0$ & $\beta 1$ & $\mathrm{R}^{2}$ & \multicolumn{2}{|l|}{} \\
\cline { 3 - 6 } & & & & Table schedule \\
\hline System MRP & 0.134 & $\begin{array}{l}.0964 \\
(30.095)\end{array}$ & 0.930 & 905.018 & 3.42 \\
\hline
\end{tabular}

$\mathrm{P} \leq 0.05 \mathrm{~N}=70 \mathrm{dF}(1,68)$ *

Refers to the value of $\mathrm{T}$ Calculated

Source: Prepared by researchers in the light of computer results.

Table (5) shows that overall quality management as an independent variable significantly affects the MRP system as a certified variable, and this is supported by the calculated value of $\mathrm{F}$ (905.018). It is a significant value greater than 
its scheduled value of (4.42) at the degrees of freedom (1.68) and significant level (0.05) and the value of the R2 selection factor of (0.930). It indicates that (93\%) One of the differences explained in the MRP system in the research laboratory is to manage overall quality. The rest is due to random variables that cannot be controlled or are not included in the regression model in the first place. By tracking the value of $\beta$ and t-test, the calculated $T$ value was (30.095), which is greater than its scheduled value of 1.682 at a degree of freedom (1.68) and a significant level (0.05). Based on the above, the second main hypothesis is accepted at the level of the researched laboratory.

\section{CONCLUSIONS}

Poor use of computers in the company's operations, making it difficult for the company to implement the MRP system. The company's management is digging to implement the concept of total quality management, and the MRP system is a positive indicator in the company. By studying correlations, we found that there were significant correlational correlations between TQM as an independent variable and the MRP system as an authorized variable The two researchers indicated a positive moral effect relationship between TQM and the MRP system. The management of the researched company should pay attention to modern technologies and introduce computerized adhesion to all its organizational levels. The necessity of introducing the concepts of total quality management and MRP system to the company and identifying the strengths and weaknesses to benefit from the strengths and overcome the weaknesses. The necessity of introducing modern systems for inventory management and distribution planning as inputs to the MRP system to coordinate the efforts of the company's various levels and work to avoid bottlenecks and delays in meeting customers' demands. Training workers at all levels of administration on modern systems such as the Total Quality Management System and MRP system by introducing them to training courses to develop their skills and encourage the introduction of modern production systems for the returns to be achieved on the company.

\section{References}

[1]. C. O’Connor, "Renewables-Finance: Export-Import Bank Has Major Role in Financing Renewable Energy," Natural Gas \& Electricity, vol. 30, no. 2, pp. 23-28, Aug. 2013.

[2]. Galstyan, "LIML estimation of import demand and export supply elasticities," Applied Economics, vol. 50, no. 17, pp. 1910-1918, Sep. 2017.

[3]. S. Tokarick, "A Method for Calculating Export Supply and Import Demand Elasticities," IMF Working Papers, vol. 10, no. 180, p. 1, 2010.

[4]. takashi sagara, "Import and Export of PhDs in Europe," Advances in Social Sciences Research Journal, vol. 2, no. 2, Feb. 2015.

[5]. M. E. Thompson, "BRCA1 16 years later: nuclear import and export processes," FEBS Journal, vol. 277, no. 15, pp. 3072-3078, Jul. 2010.

[6]. B. A. Topcu, "The impact of export, import, and renewable energy consumption on Turkey s ecological footprint," Pressacademia, vol. 8, no. 1, pp. 31-38, Mar. 2021.

[7]. B. A. Topcu, "The impact of export, import, and renewable energy consumption on Turkey s ecological footprint," Pressacademia, vol. 8, no. 1, pp. 31-38, Mar. 2021.

[8]. N. Supersberger and L. Führer, "Integration of renewable energies and nuclear power into North African Energy Systems: An analysis of energy import and export effects," Energy Policy, vol. 39, no. 8, pp. 4458-4465, Aug. 2011.

[9]. B. Lin and T. Wang, "Forecasting natural gas supply in China: Production peak and import trends," Energy Policy, vol. 49, pp. 225233 , Oct. 2012.

[10]. L. L. Bergeson, “The EPA Proposes Changes to RCRA Hazardous Waste Export and Import Regulations," Environmental Quality Management, vol. 25, no. 3, pp. 107-109, Mar. 2016.

[11]. Seunglin Hong and 이상춘, "A study on Reinfrocement Competitiveness of Import and Export through Retrenchment on Logistics Costs of Import and Export,” The Journal of International Trade \& Commerce, vol. 9, no. 7, pp. 163-186, Dec. 2013.

[12]. M. J. Christensen, "The Import/Export of Police Models: Danish 19thCentury Police Reform Between Elites of Revolution and Reaction," Journal of Historical Sociology, vol. 30, no. 4, pp. 845-867, Aug. 2016.

[13]. C. T. Thuy, "Vietnam-Asean Trade: Solutions for Vietnam's Import and Export," International Journal of Current Science Research and Review, vol. 04, no. 05, May 2021.

[14]. S. Narayan And P. K. Narayan, "Estimating Import And Export Demand Elasticities For Mauritius And South Africa," Australian Economic Papers, vol. 49, no. 3, pp. 241-252, Aug. 2010.

[15]. K. J. Fox, U. Kohli, and A. Shiu, "Trade Agreements and Trade Opportunities: A Flexible Approach for Modeling Australian Export and Import Elasticities," Review of International Economics, vol. 18, no. 3, pp. 513-530, Jul. 2010.

[16]. Y. Ogura, "Policy as a 'porter' of RE component export or import? Evidence from PV/wind energy in OECD and BRICS," Energy Economics, vol. 86, p. 104630, Feb. 2020. 